\title{
THE STUDY OF PLANT COMMUNITIES AND FLORISTIC COMPOSITION AROUND SENKELE FARIS, WEST SHEWA ZONE OF OROMIA NATIONAL REGIONAL STATE, CENTRAL ETHIOPIA
}

\section{BELETE KEBEDE SAPANE}

Research Scholar, Department of Biology, Robe College of Teacher Education, Robe, Ethiopia

\begin{abstract}
The Study of Plant Communities and Floristic Composition around Senkele Faris, West Shewa Zone of Oromia National Regional State, Central Ethiopia

This study was conducted around Senkele Faris, West Shewa Zone of Oromia Regional State. The objective of this study was to compile floristic composition and community types. Fifty two, $20 \mathrm{~m} \times 20 \mathrm{~m}$ quadrates were selected and all the plants in the quadrates were recorded. The cover abundance values were estimated. DBH, height, and density count for woody species in all the quadrates were registered. A total of 110 species belonging to 98 genera and 48 families were recorded from 52 sample plots and identified at the National Herbarium (ETH), Addis Ababa University. The Asteraceae family was represented by the highest number of species (16) followed by Fabaceae (13) and Poaceae (8). Five community types were identified and described. The plant communities were named after two or three of the dominant species and/or characteristic species selected by their synoptic value. The plant community differed in species diversity, frequency of occurrence and botanical composition of species. The Rosa abyssinica-Galium aparinoides community type had the highest species diversities whereas Vernonia amygdalin-Erythrina brucei-Juniperus procera and Bidens pilosa - Microlepia strigosa - Capparis tomentosa communities had the lowest. Shannon-Wiener diversity indices were computed to measure species diversity and it revealed that species diversity is high in communities 1, 5, 4, 2 and 3 respectively. This is probably due to high rate of disturbance in the communities.
\end{abstract}

KEYWORDS: Cluster Analysis, Diversity, Dominant Species, Floristic Composition, Vegetation, Vegetation Structure

Received: Jun 08, 2020; Accepted: Jun 28, 2020; Published: Aug 18, 2020; Paper Id.: IJMPERDJUN2020789

\section{INTRODUCTION}

Plant community as mentioned by Kent and Cooker (1992) can be defined as the collection of plant species growing together in a particular location that shows a clear relationship with each other. According to the two authors, the species compositions of the communities better express their relationships to one another and environment than any other characteristics. Ethiopia's vegetation reflects the great differences in the country's altitude. A careful analysis of vegetation is a means of revealing important information about other components of the ecosystem (Goldsmith et al., 1986). According to Kershaw, 1973, vegetation study could promote selecting and employing the appropriate conservation and management plan for sustainable use of ecosystems. Floristic data are relevant for establishing the present situation for environmental impact assessment as well as for monitoring changes in ecosystem quality in terms of changing species composition. 
As mentioned by Zerihun Woldu et al. (2002) and Zewge Teklehaimanot and Healey (2001), Ethiopia is rich with fauna and flora because of its diverse ecological features, which make the country an important centre of diversity and endemism. As it is known, Ethiopia is strategically located in the Horn of Africa, and has the vital conditions for developing good quality tropical forests (Legesse Negash, 2010). Vegetation types are with intermediate characteristics between savannahs and woodlands are shrublands and bushlands (Engeles and Hawkes, 1991). Seasonal distribution of rainfall and amount of rainfall are crucial factors to vegetation development (Young and Giese, 1990) in Ethiopia. The most abundant species in the study area therefore, are those of greatest physiological endurance of the given range of conditions.

Vegetation in Ethiopia encompasses four main biomes, which are found across the country's regions. The first one is savanna, consisting of montane tropical vegetation with dense forests and rich undergrowth. It also consists of tropical dry forests mixed with grassland at lower elevations of the Western and Eastern Highlands. The second biome is comprised of mountain vegetation, mostly montane and temperate grasslands, covering the higher altitudes of the Western and Eastern Highlands. The third biome is made up of tropical thickets and wooded steppe, and is found in the Rift Valley and Eastern Lowlands. The fourth biome is desert steppe vegetation, covering areas of the Denakil Plain.

(http://earthobservatory.nasa.gov/Experiments/Biome/bioshrubland.php)

The study area which is Senkele Faris is one of the areas where the ecological vegetation is characterized by shrubland. The shrub lands including the study area are made up of shrubs or short trees. There is usually not enough rain to support tall trees. Shrub lands are usually fairly open so grasses and other short plants grow between the shrubs. Misra (1974) noted that one of the essential and most important aspects of ecological investigation is the study of vegetation. Goldsmith \& Harisson (1976) also stated that vegetation being an essential component of an ecosystem needs careful study and analysis since such study is used as a means of revealing useful information about vegetation of an area and ecosystem.

The study area is one of the areas where one finds high number of plant species diversity. This kind of vegetation is highly valued for its high economic and ecological services. In spite of these services, shrubland vegetation removal of this study area will apparently continue like the other parts of the country unless important measure is taken (personal observation and communication with local inhabitants). Therefore, detailed biodiversity and ecological studies are important to sketch the attention of policy makers to understand the ecosystem services of this biodiversity crowed and carryout appropriate conservation measures.

The loss of vegetation cover on the central plateau including the study area due to the long history of sedentary agriculture has resulted in soil erosion. West Shewa (Senkele Faris), as part of the central highland has been faced with such challenge and the long time cultivation of crops and the highland sharply slopes are also among the factors that contributed to the sad situations that in return contributes to the climate changes of today. To overcome the condition, different stakeholders from grass root level to state, as well as internationally are expected to do their stake. Based on this background and baseline, this study was undertaken aiming at describing and providing available floristic information about shrubland vegetation around Ambo, including some impacts on the vegetation of the study area. The information is supposed to be important for further studies by any interested body, taking maintenance measurements, formulating and put into practice relevant policies, improving vegetation resources, etc. 


\section{MATERIALS AND METHODS}

\section{Description of the Study Area}

The study sites, namely Awaro Kora Kebele (Tulu Facha Shrubland), Senkele Faris Kebele (Senkele \& Teltele Shrubland), Gosu Kora Kebele (Tulu Miessa Shrubland) and Kisose Ido

Liban Kebele (Wadessa Shrubland) is located in the study area of West Shewa Zone of Oromia Region. The West Shewa Zone is endowed with a high potential for agriculture.

Senkele Faris is located $112 \mathrm{kms}$ West of the capital Addis Ababa, on the road to Nekemt and popular for its immense natural gifts including excellent climate which provides comfortable living and working environment. The town is also famous for its mineral water which is bottled outside of town and widely consumed all over the world. (http://maps.thefullwiki.org/Ambo, Ethiopia).

Ambo lies at latitude of $8^{0} 59^{\prime} \mathrm{N}$ and longitude of $37^{0} 51 \mathrm{E}$ at an elevation of $2101 \mathrm{~m}$ (6893ft) and the District covers a total area of about 83,598.69 hectares (Office of Agricultural \& Rural development of Ambo District- 2002 SPM Information). The study area District lies approximately between latitudes $8^{0} 54^{`}$ and $8^{0} 59^{`}$ North and longitudes $37^{\circ} 48^{\circ}$ and $38^{\circ} 02^{`}$ East.

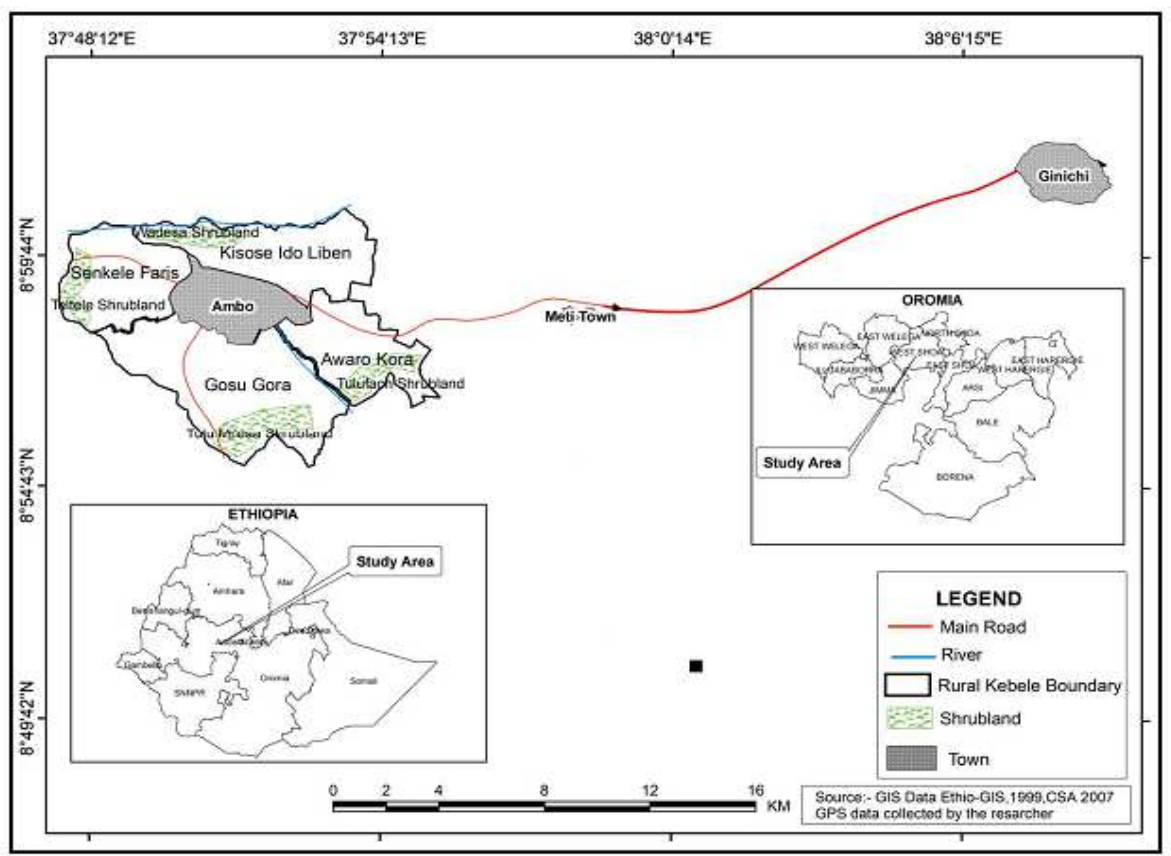

Figure 1: MAP Of ETHIOPIA AND WeSt SheWa ZoNe Showing STUdy AREa (SOURCE: AdAPTED From Gis DATA ETHIO-GIS, 1999, CSA 2007).

\section{Topography}

The study area has diverse topography and this diversity of landscape contributes to the slight variation of natural vegetation by determining local variations in climate and soil composition (personal observation). Tullu Facha is estimated to be $15 \mathrm{~km}$ away from Ambo town in the eastern direction. It has a moderate slope and the land has been cultivated for vegetables with some grass-covered areas mainly used for the grazing of cattle. Senkele, which is about $6 \mathrm{~km}$ west of Ambo, has a gentle slope and the land has been used for only three years for the cultivation of maize whereas Tullu Miessa 
shrubland (Gosu Kora Kebele) is estimated to be $10 \mathrm{~km}$ away from Ambo town in the southern direction. It has a moderate slope and has been cultivated continuously for 11 years for teff and wheat (Attah, 2010).
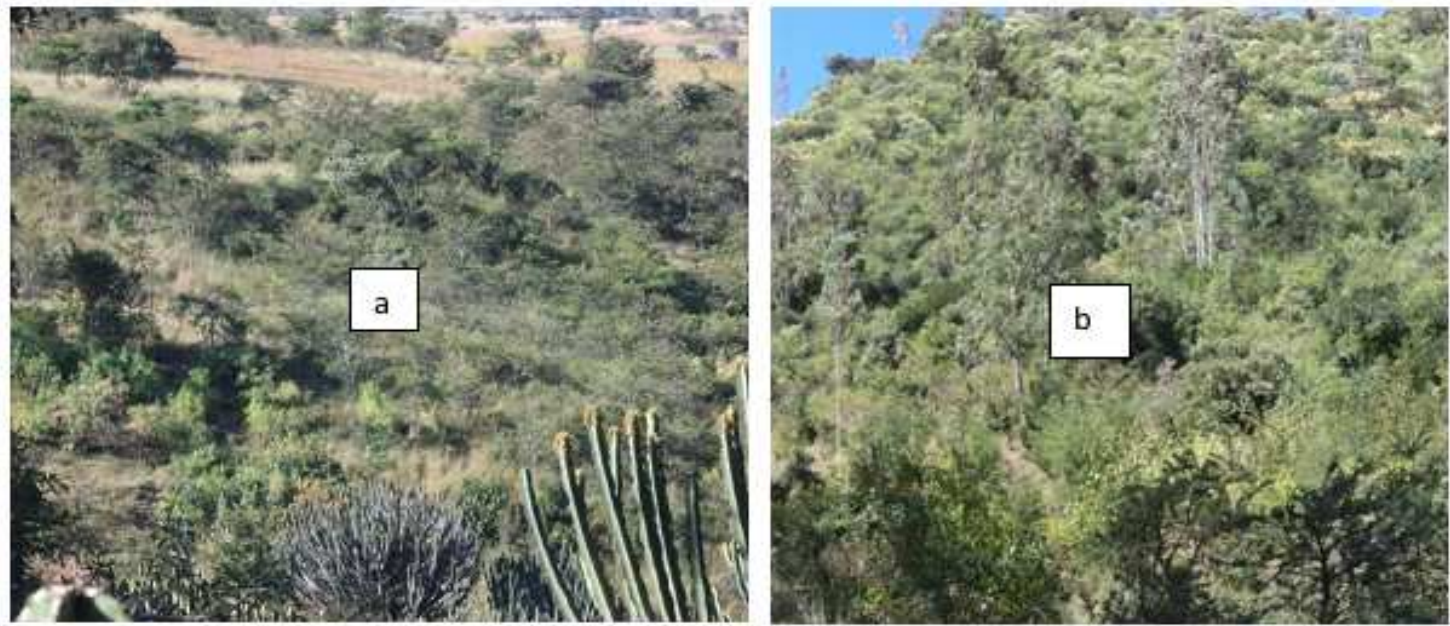

Figure 2: Senkele FARis ARea(A) AND Tulu Miessa AREa SHRUblands(B) : Photo taken by BELETE KEBEDE.

\section{Climate of the Area}

Despite its proximity to the equator, Ambo enjoys a mild, Afro-Alpine temperate and warm temperate climate (Prabu et al., 2010).

Analysis of the meteorological data result showed that the mean annual temperature of the study area is about $20.1^{\circ} \mathrm{C}$, ranging from a mean minimum of $10.3{ }^{\circ} \mathrm{C}$ to mean maximum of $29.80 \mathrm{C}$. The mean annual rainfall of the area is $1129 \mathrm{~mm}$ year -1 . The lowest mean temperature over thirteen years was $10.3{ }^{\circ} \mathrm{C}$ recorded in November, whereas the highest was $29.8^{\circ} \mathrm{C}$ recorded in March.

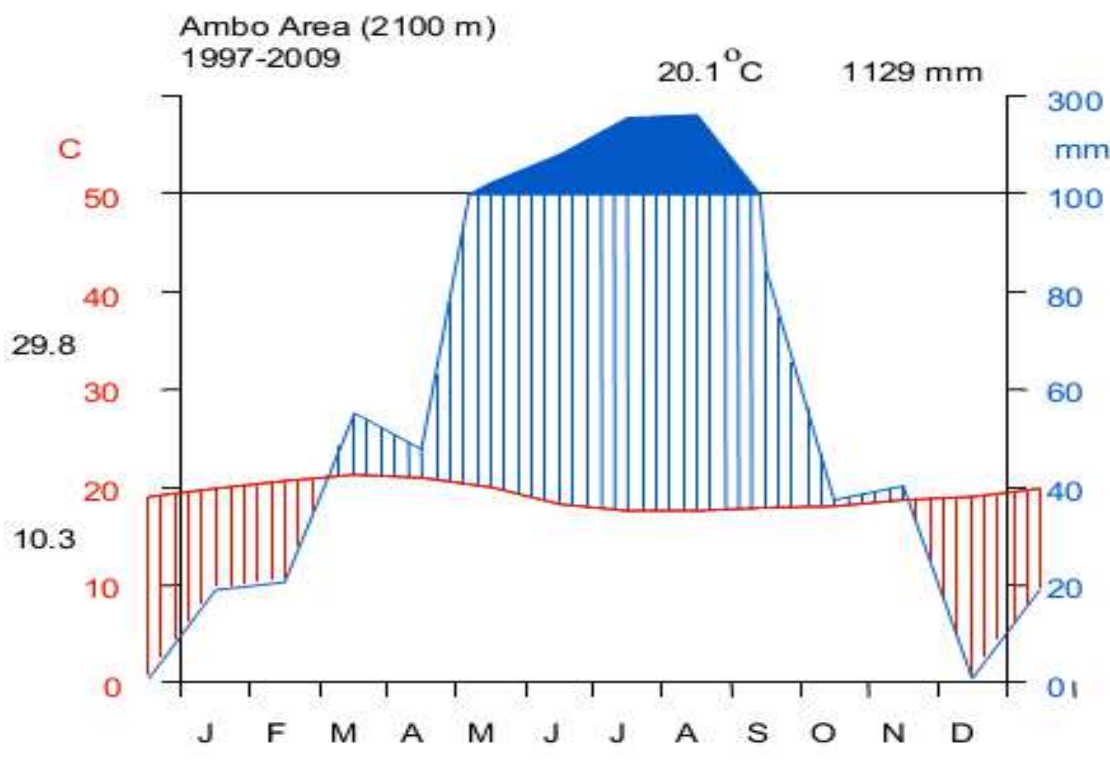

FIGURE 3: CLIMATE DIAGRAM SHOWING RAINFALL DISTRIBUTION AND TEMPERATURE VARIATION FROM 1997-2009 AT AMBO STATION. SOURCE: Data obtained from National Meteorological AgenCy, 2011/12. 


\section{Vegetation}

Vegetation of the study area is patchy and composed of small to medium sized shrub species dominated with some scattered tree species. Vegetation is characterized by shrublands which are made up of shrubs or small trees and are usually fairly open; grasses and other small plants grow between the shrubs (personal observation). The vegetation description stated by Zerihun Woldu and Backéus (1991) shows that the study area is characterized by dry evergreen montane forest on the basis that the dry evergreen montane forest covered the area between 1500 and $3000 \mathrm{~m}$ a.s.l. in the central and northern part of the country.

The common plant species of the study area comprise Olea europaea subsp. cuspidata, Albizia schimperiana, Acacia spp., Carissa spinarum, Cordia africana, Olinia rochetiana, Croton macrostachyus,Ptrerolobium spp.,Maytenus arbitifolia, Clausena anisata, Osyris quadripartita, Maesa lanceolata, Vernonia spp., Ficus spp, Phoenix reclinata, Premna schimperi, Myrsine africana, Bersama abyssinica, Calpurnia aurea and different shrubs and herb species. In line with this, Zerihun Woldu and Backeus (1991) stated that the whole shrubland is characterized by Carissa spinarum, Maytenus arbutifolia, Myrsine africana and Olea europaea. Evenif the area is well known by natural vegetation, there are also few plantations of Eucalyptus spp. and Grevillea spp. particularly in Tulu Miessa shrubland site.

\section{Sampling Design and Data Gathering Techniques}

Data of vegetation were collected from sample plots of five sample sites (patches) found around Ambo. These study sites were selected by preferential sampling technique by considering the amount of vegetation each site holds. Too small patches were misplaced. Quadrats of $20 \mathrm{~m}$ x $20 \mathrm{~m}\left(400 \mathrm{~m}^{2}\right)$ were laid systematically at every 20 meters interval following smaller elevation (up the hill). The number of plots was determined proportional to patch size and a total of 52 quadrates were laid out based on their size. Details of quadrates per site are presented in Table 1 below. Sample quadrates of the first two patches (Table 1) which is relatively large in size were determined after the total area of the patch is estimated and then $1 / 3^{\text {rd }}$ of the total patch area was taken to lay quadrates which could be expected to represent the whole patch.On the other hand, the size of the remaining patches (sites) was not large so that the whole area was considered to lay quadrates. The starting point of quadrate was determined randomly.

TABLE 1: SITES OF THE STUDY AREA WITH THEIR PLOT SIZE

\begin{tabular}{|l|l|r|}
\hline Patches (Sites) & Direction & No. of quadrats \\
\hline Tulu Facha shrubland & East of Ambo town & 17 \\
\hline Tulu Miessa shrubland & South of Ambo Town & 5 \\
\hline Senkele Faris shrubland & West of Ambo town & 8 \\
\hline Teltele shrubland & North-west of Ambo town & 7 \\
\hline Wadessa shrubland & North of Ambo town & 52 \\
\hline Total & & \\
\hline
\end{tabular}

Within the main quadrate, five $1 \mathrm{~m}^{2}(1 \mathrm{~m} \times 1 \mathrm{~m})$ sub quadrates; four at each corners and one at the center (Figure 4) were laid to record herbaceous plants. Cover abundance of each herbaceous species was estimated visually which were encountered in each subplots placed at the four corners and the center of the main plot. Afterwards, the total cover of a 
species in five subplots was divided by the number of subplots (5) and the result was converted to cover abundance value of Braun-Blanquat scales. So that, the same method was applied for all herbaceous species of the study area. All woody \& herbaceous plant species were recorded and visual estimates of percent cover for each woody plant were recorded using the $400 \mathrm{~m}$ plot. Percentage cover was estimated as a vertical projection onto the ground of all above ground parts of the individual plant species.

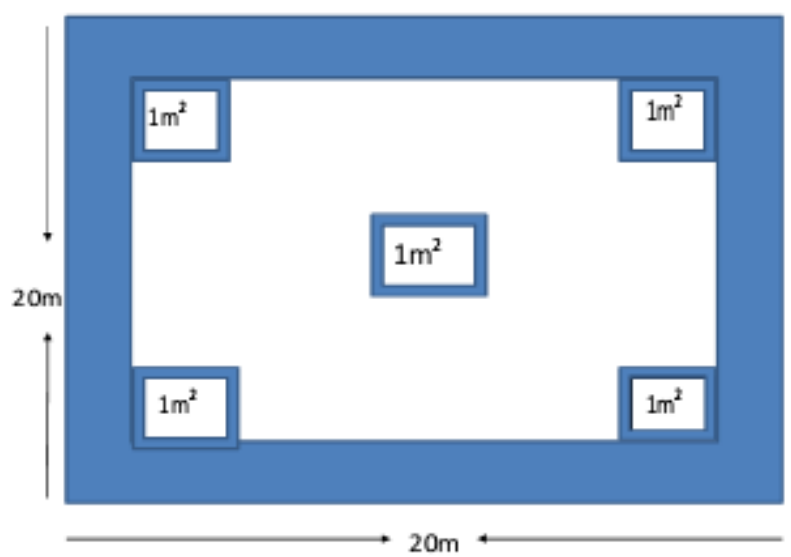

FigURE 4: LAYOUT OF THE STUDY QUADRATE OF ALL PATCHES OF THE STUDY AREA.

\section{Floristic Data Collection}

All plant varieties such as herbs, shrubs, lianas, epiphytes, ferns and trees in each quadrate were recorded. The vernacular (local) names were used when available. In the study area, physiographic variables such as altitude and geographical coordinates were measured for each quadrate using Garmin GPS 60.

\section{Plant Specimen Identification}

Specimens were collected, numbered, pressed, and dried for identification in the herbarium room in Addis Ababa University. Local people were participated in species identification using local names and the corresponding scientific names were checked in the National Herbarium (ETH) of Addis Ababa University and identified by comparison with authenticated specimens, illustrations and with the assistance of advisor and finally deposited there with their labels after confirmation.

\section{Structural Data Collection}

Each individual was counted, their circumference was measured and the height of each tree above $2 \mathrm{~m}$ was taken. The number, height, $\mathrm{DBH}$ (diameter at breast height) $>2 \mathrm{~cm}$ were documented for each tree individuals in the plots. Percentage cover of trees, shrubs and herbs were estimated in the field by visual observation and latter converted to cover/abundance values of Braun-Blanquet scales as modified by van der Maarel (1979). This new cover-abundance scale is an effective, easy to use directly in the field and the raw data can be easily entered into the data-processing system for vegetation community classification.

Accordingly, the scale represents:

$1=$ rare, generally one individual,

$2=$ occasional or sporadic with less than $5 \%$ cover of the total area, 


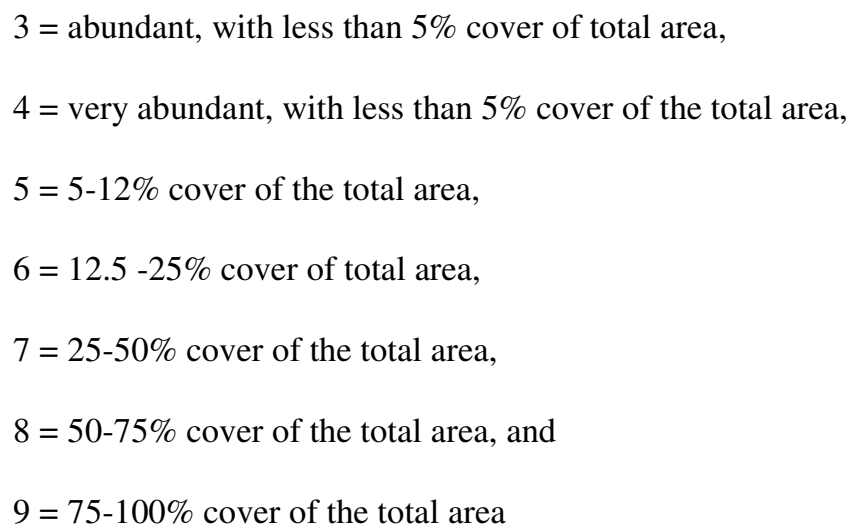

\section{Vegetation Data Analysis}

All individuals recorded in all the 52 quadrates were used in the vegetation data analysis. The vegetation classification was done using cover abundance values. The collected data for each plant species which were originally identified and recorded in the form of percent cover values were converted into abundance values of Braun Blanquet (1965) Scales modified by van der Maarel (1979). Furthermore, a floristic approach of Braun-Blanquet scale was used to determine the relative cover proportion of individual species for each community types.

As a result, a hierarchical cluster analysis (classification) was performed to classify the vegetation into plant community types. A traditional table analysis was also computed.

Abundance data of each individual were used for cluster analysis as input. The community types distinguished were further refined in a synoptic table where each column represents a community type and species occurrences were summarized by synoptic cover-abundance values.

\section{Plant Community Analysis}

Thus, multivariate techniques (Hierarchical cluster analysis or classification) were employed to study the complex nature of plant communities, with the general objectives of summarizing large complex data sets obtained from community samples, helping in the interpretation of the data and the generation of hypothesis about community structure and variation (Lambert and Dale, 1964 ; Greig-Smith, 1964). Of these multivariate methods employed to study the complex nature of communities, classificatory techniques were employed to analyze the vegetation data of shrubland vegetation around Senkele Faris.

\section{Structural Data Analysis}

For structural data analysis of vegetation species densities, height, and diameter at breast height (DBH) were used for description of vegetation structure. All trees with a DBH greater than $2 \mathrm{~cm}$, and height greater than $2 \mathrm{~m}$ were measured for DBH. Species composition and size class show the likely state of the vegetation of a site (Enright, 1982). The purpose of using size class distributions in DBH is used to investigate the regeneration status of the woody plant species (Peters, 1996).

Accordingly, DBH, which was measured using ordinary measuring meter tape and calculated by dividing the circumference of the woody species, measured at about $1.3 \mathrm{~m}$ heights above the soil surface by $\pi$ following Martin (1995).

Circumference $(C)=\pi \mathrm{d}$, where $\mathrm{d}$ is diameter at breast height and $\pi=3.14$ 


\section{RESULTS AND DISCUSSIONS}

\section{Floristic Composition}

A total of 110 plant species representing 98 genera and 48 families were recorded. The major families were Asteraceae represented by 16 species (14.5\%), Fabaceae by 13 species (11.8\%), Poaceae by 8 species (7\%), Lamiaceae by 7 species (6.4\%), and Rubiaceae by 5 species (4.5\%). See a complete list in the Appendix. The rest of the families were represented by one to four species. Most of the recorded families belonged to angiosperms except two families namely, Dennstaedtiacceae (fern) and Cupressaceae (gymnosperm). From all the species collected 32.73\% were herbs, $18.2 \%$ trees, $4.6 \%$ trees/shrubs and $39.1 \%$ were shrubs.

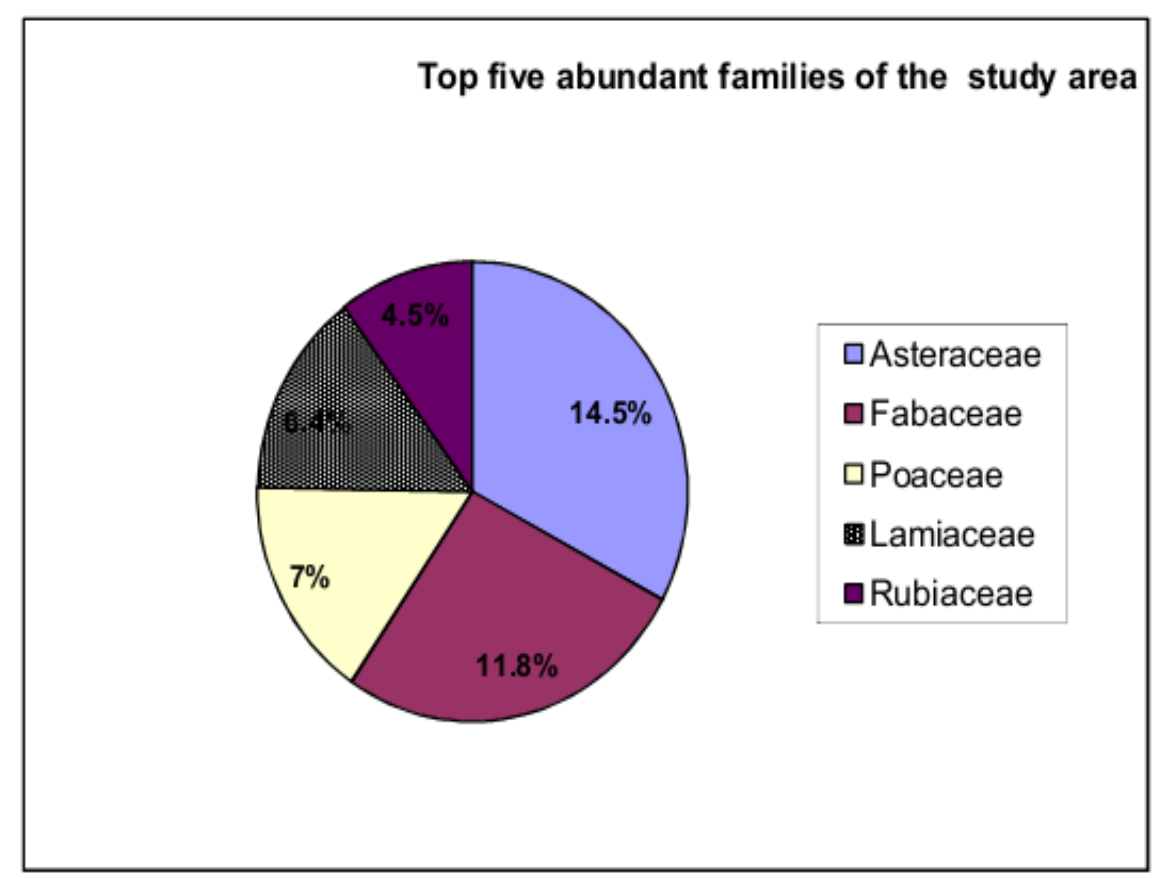

Figure 5: PERCENTAGE OF THE TOP FIVE ABUNDANT F AMILIES HAVING HIGH SPECIES NUMBER IN THE STUDY AREA.

As indicated in figure 5, Asteraceae was the highest abundant family represented by 16 species (14.5\%), followed by Fabaceae that contributed 13 species $(11.8 \%)$ while the rest are represented by less than ten species.

\section{Vegetation Classification (Plant Community Types)}

Based on the analysis of abundance data of species, five plant community types (clusters) were identified from the classification strategies. These include community types 1, 2, 3, 4, and 5. This shows that the sample quadrates that are close together correspond to sites that are similar in species composition and hence belong to the same community. The community types varied in size, ranging from 5-17 plots. 
Agglomerative Herarchical Classification Using SR

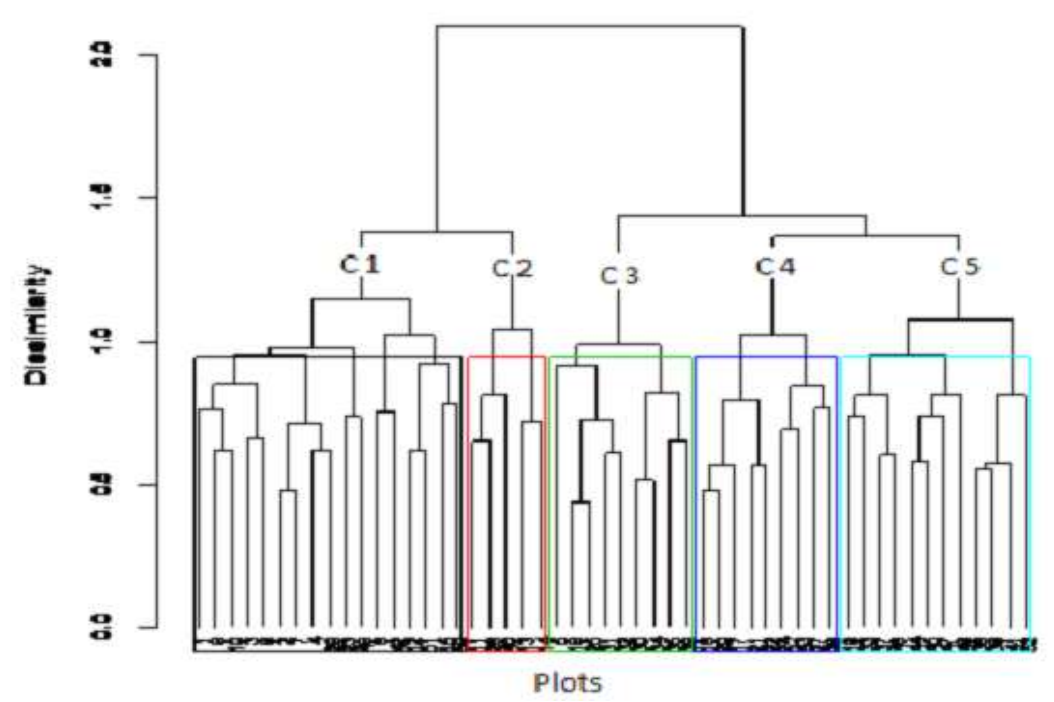

FIGURE 6: DENDROGRAM SHOWING COMMUNITY TYPES OF THE STUDY AREA.

The plot code and arrangement of plots along the dendrogram of each community type are as follows:

C1: (plots 1, 2, 3, 4, 6, 7, 8, 9, 10, 12, 15, 23, 28, 42, 48, 50, 51)

C2 : (Plots 11, 13, 14, 26, 40)

C3: (Plots 5, 18, 25, 30, 31, 32, 34, 35, 38)

C4: (Plots 16, 17, 20, 21, 22, 24, 27, 29, 43)

C5: (Plots 19, 33, 36, 37, 39, 41, 44, 45, 46, 47, 49, 52)

The five clusters were designated as plant community types based on the values of their synoptic cover. Diagnostic species of each community types are given in Table 2.

Table 2. Synoptic cover-abundance values of diagnostic species and other species having a value of $>2.0$ in at least one community type. 
Table 2

\begin{tabular}{|l|r|r|r|r|r|}
\hline Community types & 1 & 2 & 3 & 4 & 5 \\
\hline Community size & 17 & 5 & 9 & 9 & 12 \\
\hline Acacia dolichocephala & 0.00 & 0.00 & 0.00 & $\mathbf{2 . 0 0}$ & 0.88 \\
\hline Albizia schimperiana & 0.69 & 0.00 & 0.00 & 1.86 & 2.63 \\
\hline Bidens pilosa & 0.00 & $\mathbf{2 . 5 0}$ & 0.71 & 0.29 & 0.00 \\
\hline Bidens prestinaria & 0.23 & 2.00 & 0.71 & 0.29 & 0.25 \\
\hline Calpurnia aurea & 0.54 & 0.00 & 1.43 & 2.29 & 3.19 \\
\hline Capparis tomentosa & 0.00 & $\mathbf{2 . 0 0}$ & 0.57 & 0.00 & 0.44 \\
\hline Carissa spinarum & 1.08 & 3.50 & 3.43 & 1.64 & 1.88 \\
\hline Croton macrostachyus & 0.00 & 1.50 & 0.57 & 3.71 & 4.06 \\
\hline Cynodon dactylon & 0.31 & 0.00 & 2.57 & 1.79 & 1.56 \\
\hline Erythrina brucei & 0.00 & 0.00 & $\mathbf{1 . 4 3}$ & 0.00 & 0.00 \\
\hline Euphorbia abyssinica & 0.46 & 0.00 & 0.57 & 2.79 & 0.38 \\
\hline Galinsoga quadriradiata & 0.15 & 3.00 & 0.57 & 0.29 & 0.00 \\
\hline Galium aparinoides & $\mathbf{0 . 5 4}$ & 0.00 & 0.00 & 0.00 & 0.00 \\
\hline Hypoestes forskaolii & 0.69 & 2.00 & 0.71 & 0.00 & 0.13 \\
\hline Juniperus procera & 0.00 & 0.00 & $\mathbf{0 . 8 6}$ & 0.00 & 0.00 \\
\hline Maesa lanceolata & 3.38 & 3.50 & 0.00 & 0.36 & 0.00 \\
\hline Microlepia strigosa & 0.15 & $\mathbf{1 . 0 0}$ & 0.00 & 0.00 & 0.00 \\
\hline Olea europaea & 2.15 & 3.50 & 2.14 & 1.71 & 1.06 \\
\hline Pennisetum riparium & 1.62 & 0.00 & 0.43 & 3.14 & 1.00 \\
\hline Pennisetum villosum & 0.00 & 0.00 & 0.00 & $\mathbf{0 . 7 9}$ & 0.00 \\
\hline Phytolacca dodecandra & 0.00 & 0.00 & 0.00 & 0.00 & $\mathbf{0 . 7 5}$ \\
\hline Premna schimperi & 0.00 & 0.00 & 1.43 & 1.36 & 2.88 \\
\hline Pterolobium stellatum & 0.00 & 1.50 & 1.71 & 0.93 & 2.94 \\
\hline Rhus vulgaris & 2.15 & 3.50 & 0.57 & 0.43 & 0.56 \\
\hline Rosa abyssinica & $\mathbf{3 . 9 2}$ & 0.00 & 0.00 & 0.00 & 0.00 \\
\hline Rubus steudneri & 0.77 & 3.00 & 0.57 & 0.21 & 0.50 \\
\hline Rytigynia neglecta & 0.00 & 0.00 & 0.00 & 0.00 & $\mathbf{0 . 8 1}$ \\
\hline Vernonia amygdalina & 0.62 & 0.00 & $\mathbf{2 . 1 4}$ & 0.00 & 0.00 \\
\hline Vernonia auriculifera & 0.77 & 3.50 & 2.00 & 1.36 & 1.19 \\
\hline & & & & & \\
\hline
\end{tabular}

*Number of quadrates grouped in each community type; highlighted numbers (values in bold) in the table represent the diagnostic species which preferably occur in a single vegetation unit (character species) or in a few vegetation units (differential species) i.e., species with high degree of fidelity (the degree to which species are confined to particular group of quadrates).

Species are listed according to their alphabetical order. Finally, the following plant communities have been named by two diagnostic species based on highest mean cover/abundance value that confined to particular cluster.

- $\quad$ Rosa abyssinica- Galium aparinoides community type

- Bidens pilosa - Microlepia strigosa - Capparis tomentosa communitytype

- Vernonia amygdalina - Erythrina brucei -Juniperus procera community type 
The Study of Plant Communities and Floristic Composition around Senkele Faris,

- Acacia dolichocephala - Pennisetum villosum community type

- Rytigynia neglecta - Phytolacca dodecandra community type

\section{CONCLUSIONS AND RECOMMENDATIONS}

\section{Conclusions}

From the study of the shrubland vegetation around Senkele Faris, 110 species of plants belonging to 98 genera and 48 families were identified, of which $39.1 \%$ were shrubs, $32.7 \%$ were herbs, $18.2 \%$ were trees, $4.6 \%$ were trees/shrubs, $4.6 \%$ were climbers and $0.9 \%$ fern. These plants are largely angiosperms except one fern species and two gymnosperm species. Asteraceae had the highest number of species followed by Fabaceae. These dominant families might have well developed strategies and adaptations which helped them successfully to survive in the area. Out of 110 species four were endemic to Ethiopia.

Results of the present study revealed that the vegetation in the study area is grouped into five different community types each of which had varying degrees of species richness, diversity and evenness. The variation prevailed among communities could be due to different factors (soil moisture, altitude, anthropogenic factors, etc,). In most parts of the surveyed area evidence of exploitation (e.g. cutting and fuel wood collection) has been observed. In addition to this, the shrubland vegetation of the study area is disturbed through grazing and browsing by livestock and other human uses (personal observation).

Analysis of species population structure pointed out the variability of population dynamics in the vegetation of the area: species able to regenerate in the study area (e.g. most trees) and large and old trees with difficulties to reproduce in the environments (e.g. Ficus vasta). Furthermore, the DBH and Height-Class distribution analyses have shown that there are similar trends in both diameter and height.

In summary, the survey showed that the study area is dominated by small sized tree and shrub species in its secondary stage of development, indicating that the forest was heavily exploited and affected in the previous periods, but good regeneration is in process at the present time.

Therefore, to improve the natural diversity and structure of the area and to minimize the influence of the surrounding communities and utilize the forest resources sustainably for present and future generation, the basic needs and traditional rights of the communities over the uses of vegetation resources should be recognized.

\section{Recommendations}

The following recommendations are made to meet these requirements:

- The major threats of the vegetation were expansion of farm land, clearing for charcoal, construction.

- Analysis of species structure shows that some important tree species like Ficus vasta and Cordia africana were in poor regeneration This calls for the need to take proper conservation measures by the relevant authorities.

- The study area has been found to possess scattered trees dominated by grass and shrubs. This floristic composition is supposed to be susceptible to over browsing and expansion of farmland. Thus, the local people should be aware about protection and sustainable way of utilization of the vegetation supported by rules and regulations. 
- Due to time and financial constraints this study is just small portion. Therefore, further study is important to fill the gap of this work and to investigate what other factors would influence the distribution of the vegetation in the study area.

\section{REFERENCES}

1. Attah, L. E. (2010). Physicochemical characteristics of the rhizosphere soils of some cereal crops in Ambo Woreda, West Shoa, Ethiopia.

2. Maejo International Journal of Science and Technology, 4(1), 93-100

3. Braun-Blanquet, J. (1965). Plant Sociology, 3rd ed. Hafner Publishing Co., NewYork.

4. Engeles, J and Hawkes, J. G. (1991). Genetic Resources of Ethiopia. In: Plant Genetic Resources of Ethiopia. Cambridge university press, pp.85, (Engeles, J and Hawkes, J. G. eds). Cambridge. Google Book.

5. Enright, N. J. (1982). Recognition pathways in forest communities using site class ordination Vegetation. 48: 133-140.

6. Goldsmith, F. B. and Harisson, C. H. (1976). Description and Analyssis of Vegetation. In: Methods in Plant Ecology (Champman, S.B. ed.) pp 85 - 155. Blackwell Scintific Publications, London.

7. Goldsmith, F. B., Harrison, C. M. and Morton, A. J. (1986). Description and analysis of vegetation. In: Methods in Plant Ecology, pp. 437-524 (P.D. Moore, ed.), second edition. Blackwell Scientific Publication, Boston.

8. Greig-Smith, P. (1964). Qualitative plant Ecology (2nd Ed.) Butterworths, London.

9. Kent, M. and Cooker, P. (1992). Vegetation description \& analisis. A practical 65 approach. Jhon Wiley and Sons, New York

10. Kershaw, K.A. (1973). Quantitative and dynamic ecology. Edward Arnold, London.

11. Lambert, J. M. and Dale, M. B. (1964). The use of Statistics in phytosociology.Advances in Ecological Research. 2: 59-99.

12. Legesse Negash (2010). A selection of Ethiopia's indigenous trees. Biology, uses and propagation techniques. Addis Ababa University Press.

13. Martin, G.J. (1995). Ethnobotany: a methods manual. Chapman and Hall, London. 268pp.

14. Misra, K. C. (1974). Manual of plant ecology. Oxford \& IBH publishing Co. New Delhi. 368 pp.

15. Peters, M. C (1996): The ecology and management of non-timber forest products. World cup technical paper no. 322. Washington D.C.

16. Prabu, P. C., Wondimu, L. and Tesso, M. (2010). Assessment of water quality of Huluka and Alaltu Rivers of Ambo, Ethiopia. J. Agr. Sci. Tech. (2011) Vol. 13: 131-138

17. Van der Maarel (1979). Transformation of cover abundance values in phytosociology and its effect on Community. Vegetation. 39: 47-114

18. Zerihun, W. and Backéus, I. (1991). The shrubland vegetation in western Shewa, Ethiopia and its possible recovery. Journal of Vegetation Science, 2: 173-180. 